\title{
Projection of Future Climate Change over Japan in Ensemble Simulations Using a Convection-Permitting Regional Climate Model with Urban Canopy
}

\author{
Akihiko Murata ${ }^{1}$, Hidetaka Sasaki $^{1}$, Hiroaki Kawase ${ }^{1}$, Masaya Nosaka ${ }^{1}$, Toshinori Aoyagi ${ }^{2}$, \\ Mitsuo Oh'izumi ${ }^{3}$, Naoko Seino ${ }^{1}$, Fumitake Shido ${ }^{1}$, Kenshi Hibino ${ }^{4}$, Koji Ishihara ${ }^{2}$, \\ Hirokazu Murai $^{2}$, Souichirou Yasui ${ }^{2}$, Shunya Wakamatsu ${ }^{5}$, and Izuru Takayabu ${ }^{1}$ \\ ${ }^{1}$ Meteorological Research Institute, Tsukuba, Japan \\ ${ }^{2}$ Japan Meteorological Agency, Tokyo, Japan \\ ${ }^{3}$ Meteorological College, Kashiwa, Japan \\ ${ }^{4}$ The University of Tokyo, Kashiwa, Japan \\ ${ }^{5}$ Ministry of Education, Culture, Sports, Science and Technology, Tokyo, Japan
}

\begin{abstract}
This study investigates future changes in temperature and precipitation extremes over Japan by the end of the 21 st century using ensemble simulations under the Representative Concentration Pathway 8.5 scenario projected by a convection-permitting regional climate model with a grid spacing of $2 \mathrm{~km}$.

For all ensemble members, the projected future climate indicates robust increases in the 99th percentile of hourly temperature over all regions of Japan. In contrast, the 99th percentile of hourly precipitation increases over the northern and part of the eastern regions of Japan, particularly on the Sea of Japan side of northern Japan in July. A couple of local-scale areas in Hokkaido are identified as a cause of significant increases in rainfall over this region.

Increases in horizontal convergence near the surface and in the middle troposphere are responsible for increased heavy precipitation over a local-scale area of Hokkaido in July. The enhanced convergence near the surface can be attributed to strengthened westerly wind, whereas that in the middle layer can be explained by vertically unstable layers.

(Citation: Murata, A., H. Sasaki, H. Kawase, M. Nosaka, T. Aoyagi, M. Oh'izumi, N. Seino, F. Shido, K. Hibino, K. Ishihara, H. Murai, S. Yasui, S. Wakamatsu, and I. Takayabu, 2017: Projection of future climate change over Japan in ensemble simulations using a convection-permitting regional climate model with urban canopy. SOLA, 13, 219-223, doi:10.2151/sola.2017-040.)
\end{abstract}

\section{Introduction}

Ensemble simulations for future projections of regional climate change have recently been performed using regional climate models with a grid spacing below $10 \mathrm{~km}$. For example, Murata et al. (2015) conducted ensemble regional climate projections over Japan using the non-hydrostatic regional climate model (NHRCM) developed by the Meteorological Research Institute (MRI) of the Japan Meteorological Agency (JMA), with a grid spacing of $5 \mathrm{~km}$. Their experiment design allowed them to project future climate change with a range of possibilities. However, one disadvantage of their study was that the model included a convective parameterization scheme, which could involve uncertainties in the projected future climate. To solve this issue, RCMs with a grid spacing of a few kilometers, known as convection-permitting RCMs, have been used (e.g., Kendon et al. 2012; Wang et al. 2013; Prein et al. 2015; Argüeso et al. 2015). Because these models do not include convective parameterization, uncertainties derived from the parameterization can be avoided.

In this study, we used the NHRCM with a grid spacing of 2

Corresponding author: Akihiko Murata, Meteorological Research Institute, 1-1 Nagamine, Tsukuba 305-0052, Japan. E-mail: amurata@mri-jma.go.jp. (C)2017, the Meteorological Society of Japan. $\mathrm{km}$ (NHRCM02) as a convection-permitting RCM, and conducted ensemble simulations to project future climate change over Japan in terms of temperature and precipitation extremes with a range of possibilities. This is the first time that long-term ensemble simulations have been performed using a convection-permitting RCM for the projections of future climate.

\section{Methods}

\subsection{Numerical model}

The NHRCM, developed by Sasaki et al. (2008), is a climate extension of the JMA nonhydrostatic model (JMA-NHM; Saito et al. 2006). The JMA-NHM is one of the numerical weatherprediction models operated by the JMA. We use NHRCM02 as a convection-permitting RCM. The specification of NHRCM02 is described in Murata et al. (2017).

\subsection{Experiment design}

The dynamical downscaling framework used in this study is as follows. The domain of NHRCM02 had $525 \times 1721$ horizontal grid points and 60 terrain-following vertical levels (Fig. 1). The lowest level was $20 \mathrm{~m}$ from the ground surface, and the highest level was $19.9 \mathrm{~km}$. Boundary conditions for NHRCM02 were derived from a simulation using NHRCM with a grid spacing of $5 \mathrm{~km}$ (NHRCM05; Murata et al. 2015). An urban canopy model (Aoyagi and Seino 2011) is used in NHRCM02 (not in NHRCM05). For long-term climate simulation, the following schemes are used: a spectral nudging scheme (Nakano et al. 2012) based on a spectral boundary coupling scheme (Kida et al. 1991; Sasaki et al. 2000), and a land-surface scheme developed by Oh'izumi (2014) updated from Hirai and Oh'izumi (2004).

Boundary conditions for NHRCM05 were provided by a simulation using an atmospheric general circulation model with 20-km horizontal resolution (MRI-AGCM3.2S, hereafter referred to as AGCM20; Mizuta et al. 2012). For both present and future climate simulations, time integrations were performed for 20 -year periods: from September 1980 to August 2000 for the present, and from September 2076 to August 2096 for the future. The integration started on 21 July and ran through 1 September of the following year. Considering the model spin-up, the simulation results of the first 42 days were removed.

Ensemble simulations for the future climate, consisting of four members, were performed under the Representative Concentration Pathway (RCP) 8.5 scenario. Each simulation was forced by boundary conditions provided by the AGCM20 simulations. The four SST fields used were a control field and three other fields (same as Murata et al. 2015). The control field (C0) was obtained from the ensemble-mean SST in the late 21 st century on the basis of CMIP5 models. The other three SST fields (C1, C2, and C3) were provided by a classification based on spatial patterns of the tropical annual-mean SST changes (Mizuta et al. 2014). 


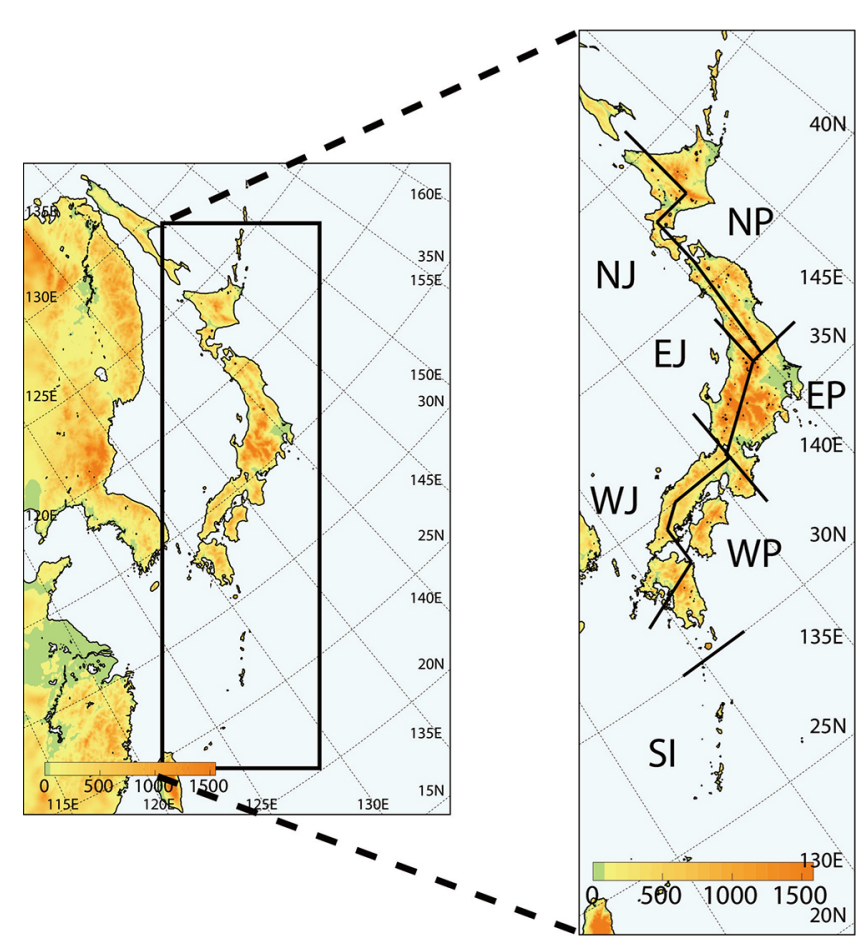

Fig. 1. Maps of NHRCM05 (left) and NHRCM02 (right) domains. Terrain is denoted by shading [m]. Local regions in the NHRCM02 domain are the Sea of Japan side of northern Japan (NJ), the Pacific side of northern Japan (NP), the Sea of Japan side of eastern Japan (EJ), the Pacific side of eastern Japan (EP), the Sea of Japan side of western Japan (WJ), the Pacific side of western Japan (WP), and the Nansei Islands (SI).

\subsection{Observational data}

The performance of NHRCM02 was evaluated using groundbased observational data from the automated meteorological data acquisition system (AMeDAS), administered by JMA, which includes data of surface air temperature (precipitation) from 700 (1200) meteorological stations covering over Japan. The average space interval of the AMeDAS network is $17 \mathrm{~km}$. The time interval of the AMeDAS data output is $1 \mathrm{~h}$ and is equal to that of the NHRCM02 output. For each station, criteria for judging whether to use the data is applied as follows: more than $50 \%$ hourly data are available in each year and this condition is satisfied more than 10 years.

For comparison, the NHRCM02 data, as well as the NHRCM05 data, corresponding to the nearest land grid point to the location of each AMeDAS station were selected. The simulated surface air temperature was corrected using a lapse rate of $0.0065 \mathrm{~K} \mathrm{~m}^{-1}$ because of height discrepancy between the model and the actual topographies, which affected model temperature.

\section{Evaluation of present climate}

The performance of NHRCM02 in surface air temperature and precipitation extremes of the present climate is assessed by comparing the simulated and observed (AMeDAS) data. As indices of hot extremes, the 99th percentile of surface air temperature (T99) for the period of a year and a month is used. Similarly, an index of precipitation extreme is defined as the 99th percentile of 1-h accumulated precipitation (P99) for a year and a month. It should be noted that the P99 calculation includes days without precipitation. Exclusion of those days can result in a misleading conclusion if future changes in days with precipitation are significant (Schär et al. 2016). We refer to T99 and P99 here as "extreme" although these indices may represent moderately extreme temperature and precipitation, respectively.

The root-mean-square error (RMSE) and mean bias (bias) in the 20-yr mean annual T99 and P99 are calculated, where a sample for RMSE and bias is collected from data over each localregion (Fig. 1), in addition to the entire area of Japan (the number of samples is equal to the number of stations). The results are compared with those for the parent model (NHRCM05). It should be noted that NHRCM05 is not a convection-permitting model because of the inclusion of the Kain-Fritsch convection scheme.

\subsection{Surface air temperature}

RMSE in T99, sampled over Japan and over the integration period (20 years), simulated by NHRCM02 is nearly equal to that obtained by the NHRCM05 simulation (AL in Fig. 2a), indicating that NHRCM02 does not adversely affect overall performance in T99. This also holds true for the annual mean temperature although RMSE in NHRCM02 is slightly larger (AL in Fig. S1a).

In contrast to RMSE, the magnitude of bias in T99 averaged over 20 years simulated by NHRCM02 is less than that derived from NHRCM05 (AL in Fig. 2b). This reduced bias is attributed mainly to those biases in the EJ, EP, WJ, and WP regions (Fig. $2 b$ ). In these regions, biases are negative in non-urban areas and
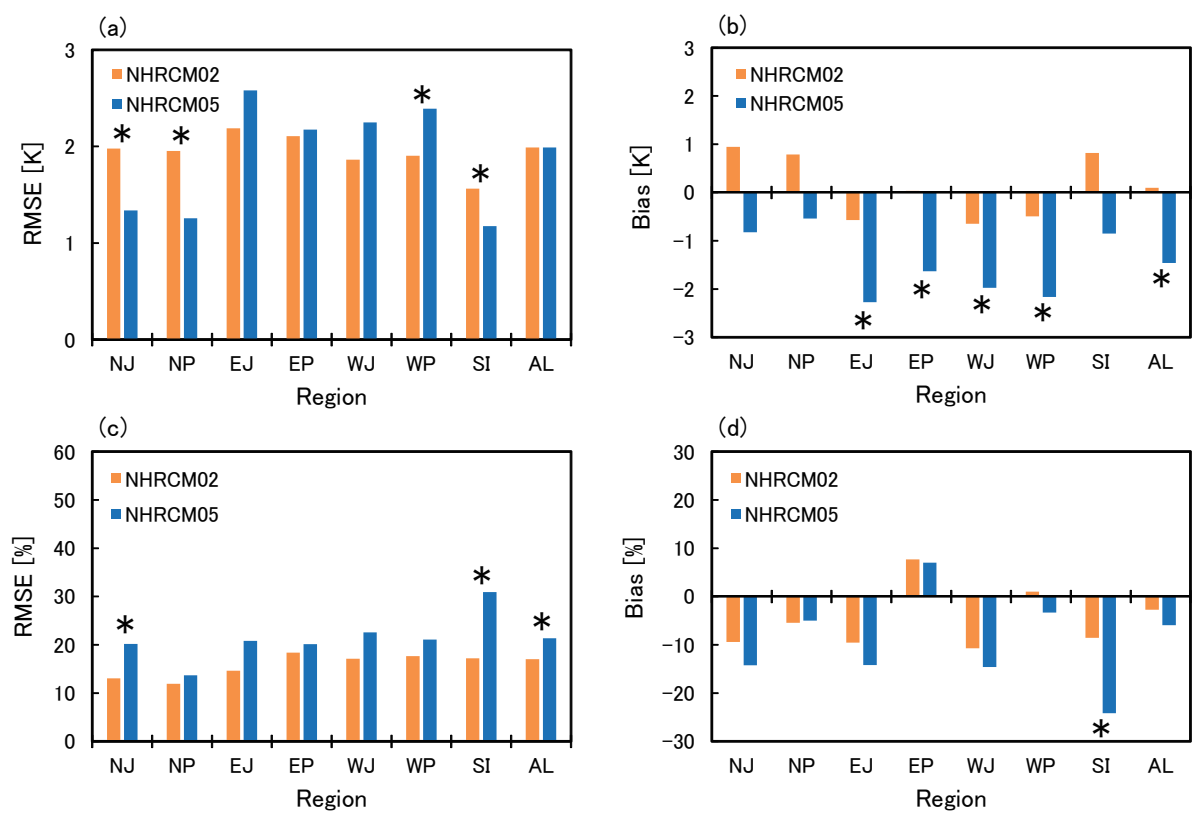

Fig. 2. (a) RMSE and (b) bias in the 20-yr mean annual T99, and (c) RMSE and (d) bias in the 20-yr mean annual P99 for each region depicted in Fig. 1, reproduced by NHRCM02 and NHRCM05. AL denotes the entire region of Japan. The asterisks denote statistical significance at the 5\% level (estimated using 10000 bootstrap samples with random replacement of 20 -yr dataset). 
positive in urban areas (Fig. S2) Contributions of two factors, urban effect and others, are of the same order, considering that the number of urban stations is smaller than that of non-urban stations. Bias in the annual mean temperature indicates that NHRCM02 does not adversely affect overall performance (Fig. S1b).

\subsection{Precipitation}

RMSE in P99 sampled over Japan for 20 years simulated by NHRCM02 is less than that obtained by the NHRCM05 simulation (AL in Fig. 2c). The difference in RMSE between NHRCM02 and NHRCM05 is statistically significant at the 5\% level. These results indicate that overall performance is improved using a higher-resolution model. RMSE in P99 for NHRCM02 averaged over each region is also less than those for NHRCM05, although the difference in RMSE between the two model simulations is significant in only the NJ and SI regions (Fig. 2c). RMSE in the annual precipitation indicates that NHRCM02 has smaller errors in all regions although the differences are not statistically significant in the EP and WJ regions (Fig. S1c).

Similarly, the magnitude of bias in P99 simulated by NHRCM02 is less than those derived by the NHRCM05 simulation over most regions (Fig. 2d). However, the difference in magnitude of bias between the two results is statistically significant in only the SI region. The magnitude of bias in the annual precipitation for NHRCM02 is also less than those for NHRCM05 over most regions (Fig. S1d). However, there are no regions where the difference between the two is statistically significant.

\section{Projection of future climate change}

\subsection{Surface air temperature}

Over all regions, the projected future climate indicated robust increases in T99, which is averaged over 20 years (Fig. 3a). These increases are statistically significant at the 5\% level in all members for each region. This holds true for the annual mean temperature (Fig. S3a). However, the rate of change in T99 is not
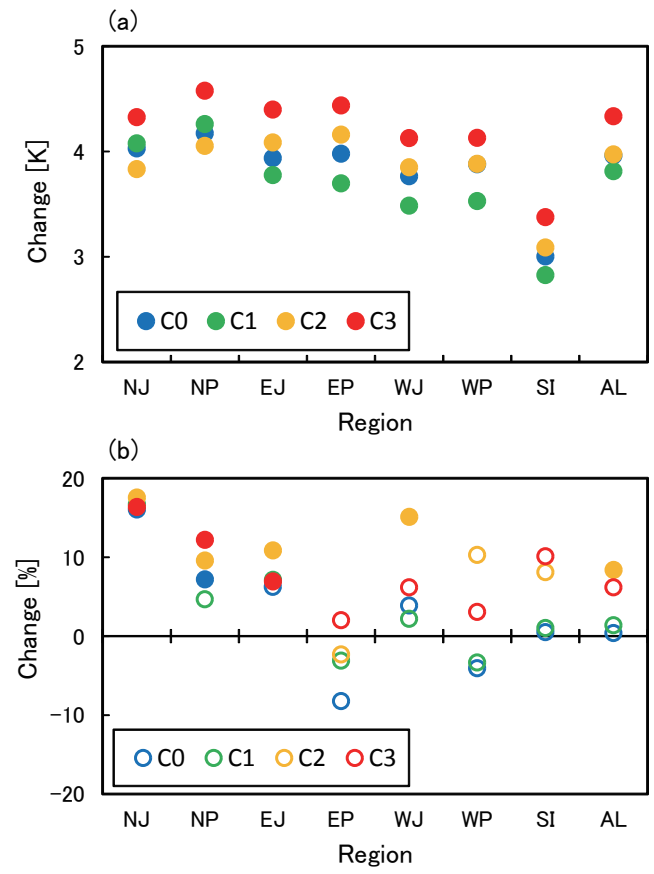

Fig. 3. Future changes in (a) the 20 -yr mean annual T99 $[\mathrm{K}]$ and (b) the 20 -yr mean annual P99 [\%] for each region depicted in Fig. 1, projected by NHRCM02. In (b), changes are defined as $100 \times($ future/present -1$)$. $\mathrm{AL}$ denotes the entire region of Japan. $\mathrm{C} 0, \mathrm{C} 1, \mathrm{C} 2$, and $\mathrm{C} 3$ denote individual ensemble members. Dots denote statistically significant changes $(5 \%$ level; estimated using 10000 bootstrap samples with random replacement of 20 -yr dataset). quantitatively comparable to that for the annual mean temperature. The data averaged over Japan (AL in Fig. 3a) are distributed at 4 $\mathrm{K}$, which is $1 \mathrm{~K}$ lower than for the annual mean temperature. This means that changes in warm extremes are lower than those in cold extremes, consistent with previous studies. For example, Kharin et al. (2013) found that cold extremes warmed more quickly over extratropical land and high-latitude oceans.

\subsection{Precipitation}

Over northern Japan and part of eastern Japan, the projected future climate exhibited robust increases in P99, which is averaged over 20 years. Changes are statistically significant at the 5\% level in all ensemble members in the NJ region and in three of the four members in the NP and EJ regions (Fig. 3b). In contrast, P99 in the other regions exhibits a statistically significant increase in one member or less. The entire area of Japan (AL in Fig. 3b) also has only one member with a statistically significant increase. The rate of change in the NJ region is the largest of all and is also robust. The results of the region are discussed below. Compared with P99, fewer regions and members exhibit statistically significant increases in the annual precipitation and the rate of increase is lower (Fig. S3b).

In the NJ region, data for July indicate that the rate of change of P99 is the largest of all and that changes in P99 are statistically significant at the 5\% level for all members (not shown). Therefore, changes in P99 in July are examined here.

Increases in P99 are projected in some areas of Hokkaido, one of four main Japanese islands (Fig. 4). Changes in P99 are larger over the northwestern and central western areas of Hokkaido, and the rate of increase is $100 \%$ in several locations. Among these locations, the rate of change of P99 is largest at the station known as Shosanbetsu. Therefore, a domain that includes this station is set for analysis (Fig. 4).

Precipitation averaged over the domain depicted in Fig. 4 is correlated with domain-averaged vertically integrated moisture flux convergence just before precipitation occurs (Fig. 5). It should be noted that data for each year are plotted when precipitation at Shosanbetsu is P99 and that the moisture flux convergence is $1 \mathrm{~h}$ earlier than the precipitation. Results indicate that the maximum precipitation exceeds $8 \mathrm{~mm} \mathrm{~h}^{-1}$ for each future climate experiment,

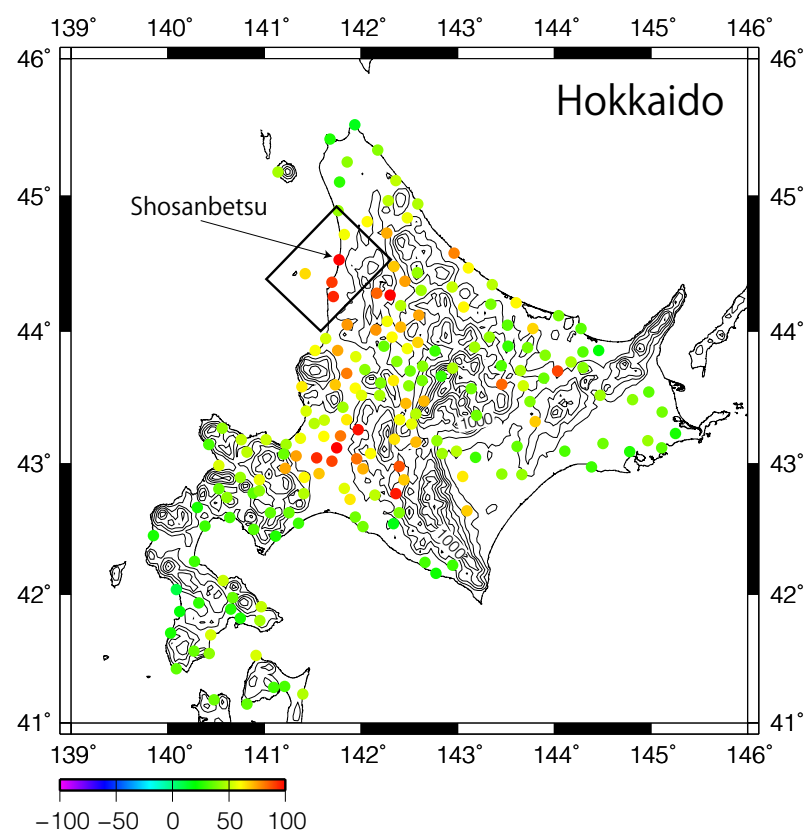

Fig. 4. Future changes in the 20-yr mean P99 [\%] in July, defined as $100 \times$ (future/present -1 ), projected by NHRCM02. The mean values of the four members $(\mathrm{C} 0, \mathrm{C} 1, \mathrm{C} 2$, and $\mathrm{C} 3)$ are plotted when the signs of all members are the same. 
which is much higher than that in the present climate $\left(5 \mathrm{~mm} \mathrm{~h}^{-1}\right)$. Meteorological situations of these five cases (one for the present climate $(\mathrm{P})$ and one for each future climate $(\mathrm{C} 0, \mathrm{C} 1, \mathrm{C} 2$, and $\mathrm{C} 3))$ are examined in detail to determine physical mechanisms for projected changes in extreme precipitation events.

Two peaks are observed in the vertical profiles of changes in moisture flux convergence of the cases mentioned above: one at $975 \mathrm{hPa}$ and the other around $600 \mathrm{hPa}$ (Fig. 6). It should be noted that the profiles represent changes in moisture flux convergence between present and future climates (future minus present), with uncertainty evaluation using four profiles. Figure 6 indicates that changes in positive moisture flux convergence in these two layers contribute to the change in vertically integrated moisture flux convergence plotted in Fig. 5. The $975-\mathrm{hPa}$ peak is also observed in the vertical profiles of monthly-mean moisture flux convergence (Fig. S4a).

Moisture flux convergence budget is analyzed using the cases mentioned above. The equation for each level used here is as follows.

$$
\begin{aligned}
\Delta\{-\operatorname{div} \cdot(q \vec{v})\}= & \Delta(-q \operatorname{div} \cdot \vec{v}-\vec{v} \operatorname{grad} q) \\
= & \Delta q(-\operatorname{div} \cdot \vec{v})+q \Delta(-\operatorname{div} \cdot \vec{v}) \\
& +\Delta \vec{v} \cdot(-\operatorname{grad} q)+\vec{v} \cdot \Delta(-\operatorname{grad} q), \ldots
\end{aligned}
$$

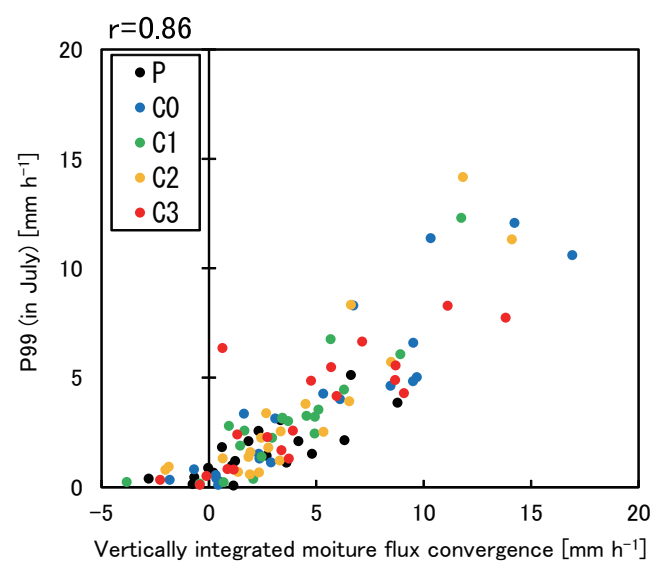

Fig. 5. Scatter diagram of vertically integrated moisture flux convergence and P99 in July for 20 years, averaged over the rectangular area depicted in Fig. 4, projected by NHRCM02. Data plotted are from a simulation for the present climate $(\mathrm{P})$ and from four-member simulations of the future climate $(\mathrm{C} 0, \mathrm{C} 1, \mathrm{C} 2$, and $\mathrm{C} 3)$.

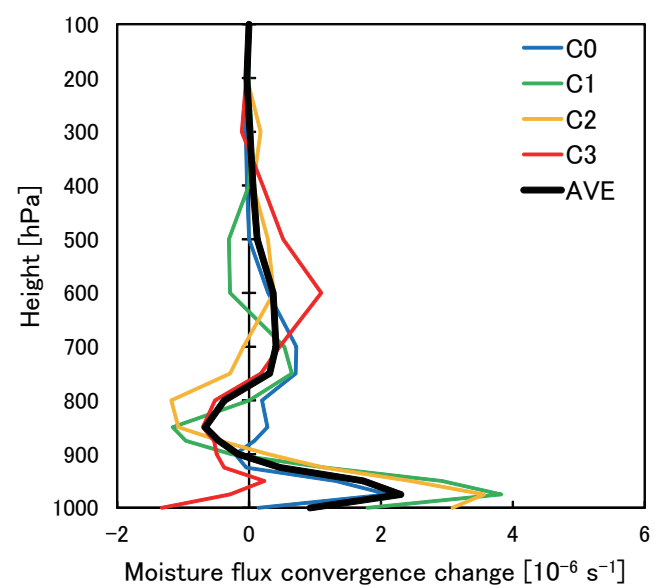

Fig. 6. Vertical profiles of changes (future minus present) in moisture flux convergence obtained from four-member simulations of the future climate $(\mathrm{C} 0, \mathrm{C} 1, \mathrm{C} 2$, and $\mathrm{C} 3)$. Here, AVE denotes the average of the four-member results. In the calculation of changes, the maximum value of 20 years is used. where $q$ is specific humidity, $\vec{v}$ is horizontal velocity, and $\Delta$ denotes the change in quantity between present and future climates (future minus present). This equation indicates that change in horizontal moisture flux convergence can be divided into four terms. The first term on the right-hand side of the equation denotes change in specific humidity; the second term denotes change in horizontal convergence; the third term denotes change in horizontal velocity vector; and the fourth term denotes change in the horizontal gradient of specific humidity.

Change in horizontal convergence is the dominant contributor to change in moisture flux convergence. Figure 7 indicates that the magnitude of the second term on the right-hand side of Eq. (1) is largest among the four terms at both the 975- and 600-hPa levels, where the left-hand side of Eq. (1) reaches its peak as mentioned above. In contrast, the magnitudes of the other terms are much smaller, indicating that the contributions of those terms are limited. In contrast, the magnitudes of the first and second terms are nearly equal for monthly-mean moisture flux convergence (Fig. S4b).

The enhanced convergence at $975 \mathrm{hPa}$ can be attributed to strengthened westerly wind. Westerly wind speed in the future climate experiments increases throughout the troposphere (Fig. S5a), whereas monthly-mean westerly wind in the same area does not show a considerable increase (not shown). Enhancement of the low-level westerly wind is responsible for larger moisture flux impinging on coastal mountains and for rising moist air to form orographic precipitation.

The enhanced convergence around $600 \mathrm{hPa}$ might be explained by vertically unstable layers. Vertical stability decreases in the future climate experiments above $800 \mathrm{hPa}$ (Fig. S5b), corresponding to the bottom of the convergence enhancement layers. Further investigation is needed to identify physical mechanisms.

\section{Summary and concluding remarks}

Future changes in hourly temperature and precipitation extremes over Japan by the end of the 21 st century under the RCP8.5 scenario were projected using NHRCM02. The performance of NHRCM02 in temperature and precipitation extremes in the present climate was first evaluated based on observations. T99 and P99 in the periods of a year and a month were averaged over 20 years and used as indices of temperature and precipitation extremes. The results were compared with those for the driving model (NHRCM05).

The magnitude of RMSE in P99 averaged over Japan simulated by NHRCM02 is less than that obtained from the NHRCM05

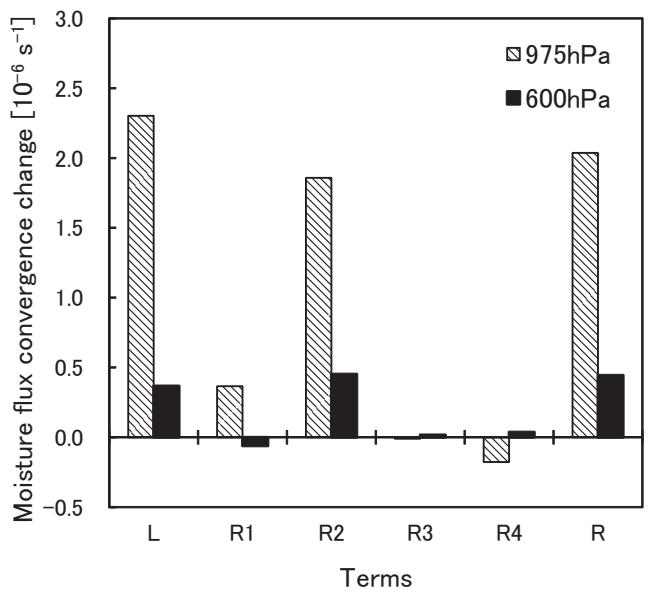

Fig. 7. Contribution of each term in Eq. (1) to moisture flux convergence changes at 975 and $600 \mathrm{hPa}$. R1 denotes the first term of the right-hand side of the equation, R2 denotes the second term, R3 denotes the third term, and R4 denotes the fourth term. L denotes the left-hand side of the equation, and $\mathrm{R}$ denotes $\mathrm{R} 1+\mathrm{R} 2+\mathrm{R} 3+\mathrm{R} 4$. 
simulation, although the difference in the magnitude of RMSE in T99 between NHRCM02 and NHRCM05 is not statistically significant at the $5 \%$ level. These results indicate that model performance is improved using the higher-resolution model, at least for extreme precipitation. This improvement might be affected by factors other than resolution and convection, such as land surface process and turbulence.

The projected future climate exhibits robust increases in T99 over all regions of Japan for all ensemble members. The magnitude of change tends to be larger over northern regions, suggesting the effects of decreased sea ice in the future climate. In contrast, P99 increases only over the northern and part of the eastern regions of Japan, particularly in the NJ region in July. Closer inspection indicates that increases in P99 in the eastern part of Hokkaido contribute mainly to those in the NJ region.

Increases in projected P99 over the northwestern part of Hokkaido in July are explained by increases in moisture flux convergence near the surface and a layer in the middle troposphere. Moisture flux convergence budget analysis indicates that change in horizontal convergence in those layers is a key factor in moisture flux convergence change. The enhanced convergence near the surface can be attributed to topography and strengthened westerly wind, whereas that in the middle layer can be explained by vertically unstable layers there.

In this study, our goal to project temperature and precipitation extremes with a range of possibilities is achieved through the use of outputs from convection-permitting RCM ensemble simulations. However, since the number of ensemble members may be insufficient, further study is required for reducing uncertainties in projections of temperature and precipitation extremes in Japan. In addition, detailed analyses of vertical profiles of moisture flux convergence are necessary for other cases.

\section{Acknowledgements}

The authors thank Osamu Arakawa and Toshiharu Nagatomo of the University of Tsukuba for their technical support. This work was conducted under SOUSEI and TOUGOU Programs of Ministry of Education, Culture, Sports, Science, and Technology of Japan.

Edited by: H. Fudeyasu

\section{Supplements}

RMSE and bias in annual mean temperature and annual precipitation are shown in Supplement 1. Bias of T99 in urban and non-urban areas are shown in Supplement 2. Future changes in annual mean temperature and annual precipitation are shown in Supplement 3. Vertical profiles and contribution of each term in Eq. (1) for changes in monthly-mean moisture flux convergence are shown in Supplement 4. Vertical profiles of changes in zonal wind speed and vertical stability are shown in Supplement 5.

\section{References}

Aoyagi, T., and N. Seino, 2011: A square prism urban canopy scheme for the NHM and its evaluation on summer conditions in the Tokyo metropolitan area, Japan. J. Appl. Meteor. Climatol., 50, 1476-1496.

Argüeso, D., A. Di Luca, and J. P. Evans, 2015: Precipitation over urban areas in the western Maritime Continent using a convection-permitting model. Climate Dyn., 47, 1143-1159.

Hirai, M., and M. Oh'izumi, 2004: Development of a new landsurface model for JMA-GSM. Extended abstract of 20th Conference on Weather Analysis and Forecasting/16th Conference on NWP. P2.22 (Available online at http://ams.
confex.com/ams/84Annual/techprogram/paper 68652.htm, accessed on 7 August 2017).

Kharin, V. V., F. W. Zwiers, X. Zhang, and M. Wehner, 2013: Changes in temperature and precipitation extremes in the CMIP5 ensemble. Climatic Change, 119, 345-357.

Kida, H., T. Koide, H. Sasaki, and M. Chiba, 1991: A new approach to coupling a limited area model with a GCM for regional climate simulations. J. Meteor. Soc. Japan, 69, 723728.

Kendon, E. J., N. M. Roberts, C. A. Senior, and M. J. Roberts, 2012: Realism of rainfall in a very high-resolution regional climate model. J. Climate, 25, 5791-5806.

Mizuta, R., H. Yoshimura, H. Murakami, M. Matsueda, H. Endo, T. Ose, K. Kamiguchi, M. Hosaka, M. Sugi, S. Yukimoto, S. Kusunoki, and A. Kitoh, 2012: Climate simulations using the improved MRIAGCM with $20-\mathrm{km}$ grid. J. Meteor. Soc. Japan, 90A, 233-258.

Mizuta, R., O. Arakawa, T. Ose, S. Kusunoki, H. Endo, and A. Kitoh, 2014: Classification of CMIP5 future climate responses by the tropical sea surface temperature changes. SOLA, 10, 167-171.

Murata, A., H. Sasaki, H. Kawase, M. Nosaka, M. Oh'izumi, T. Kato, T. Aoyagi, F. Shido, K. Hibino, S. Kanada, A. SuzukiParker, and T. Nagatomo, 2015: Projection of future climate change over Japan in ensemble simulations with a highresolution regional climate model. SOLA, 11, 90-94.

Murata, A., H. Sasaki, H. Kawase, and M. Nosaka, 2017: Evaluation of precipitation over an oceanic region of Japan in convection-permitting regional climate model simulations. Climate Dyn., 48, 1779-1792.

Nakano, M., T. Kato, S. Hayashi, S. Kanada, Y. Yamada, and K. Kurihara, 2012: Development of a 5-km-mesh cloudsystem-resolving regional climate model at the Meteorological Research Institute. J. Meteor. Soc. Japan, 90A, 339350.

Oh'izumi, M., 2014: Introduction of PBL schemes to iSiB submodel in NHRCM. Proc. of the Fall Conference of Meteor. Soc. of Japan, 172 (in Japanese).

Prein, A. F., W. Langhans, G. Fosser, A. Ferrone, N. Ban, K. Goergen, M. Keller, M. Tölle, O. Gutjahr, F. Feser, E. Brisson, S. Kollet, J. Schmidli, N. P. M. van Lipzig, and R. Leung, 2015: A review on regional convection-permitting climate modeling: Demonstrations, prospects, and challenges. Rev. Geophys., 53, 323-361.

Saito, K., T. Fujita, Y. Yamada, J. Ishida, Y. Kumagai, K. Aranami, S. Ohmori, R. Nagasawa, S. Kumagai, C. Muroi, T. Kato, H. Eito, and Y. Yamazaki, 2006: The operational JMA nonhydrostatic mesoscale model. Mon. Wea. Rev., 134, 12661298.

Sasaki, H., Y. Sato, K. Adachi, and H. Kida, 2000: Performance and evaluation of the MRI regional climate model with the spectral boundary coupling method. J. Meteor. Soc. Japan, 78, 477-489.

Sasaki, H., K. Kurihara, I. Takayabu, and T. Uchiyama, 2008: Preliminary experiments of reproducing the present climate using the non-hydrostatic regional climate model. SOLA, $\mathbf{4}$, $25-28$.

Schär, C., N. Ban, E. M. Fischer, J. Rajczak, J. Schmidli, C. Frei, F. Giorgi, T. R. Karl, E. J. Kendon, A. M. G. Klein Tank, P. A. O'Gorman, J. Sillmann, X. Zhang, and F. W. Zwiers, 2016: Percentile indices for assessing changes in heavy precipitation events. Climatic Change, 137, 201-216.

Wang, C., R. Jones, M. Perry, C. Johnson, and P. Clark, 2013: Using an ultrahigh-resolution regional climate model to predict local climatology. Quart. J. Roy. Meteor. Soc., 139, 1964-1976.

Manuscript received 31 July 2017, accepted 30 October 2017 SOLA: https://www.jstage.jst.go.jp/browse/solal 